\title{
Energy Pricing Policies and Consumers' Welfare: Evidence from Pakistan
}

\author{
Muhammad Atta-ul-Islam Abrar*, Muhsin Ali ${ }^{* *}$, Uzma \\ Bashir $^{* * *}$, and Karim Khan ${ }^{* * *}$
}

\begin{abstract}
This study analyzes the impact of energy pricing policies on consumers' welfare in rural and urban Pakistan. The study is based on pooled data from the Household Integrated Economic Survey for the period 1984/85 to 2011/12. We use the Almost Ideal Demand System to estimate parameters and price elasticities. The welfare analysis suggests that the rise in energy prices has been greater than the rise in the general consumer price index over this period. Therefore, consumers have incurred high expenditures in all years from 1984 to 2012, with a consistent welfare loss for all consumers with a decreasing trend. Additionally, the welfare loss to rural consumers is greater than that to urban consumers.
\end{abstract}

Keywords: energy pricing, welfare, almost ideal demand system, Pakistan.

JEL classification: Q41, D60, C1.

\section{Introduction}

Energy plays a vital role in a country's development and electricity and other energy resources are essential parts of a household's consumption basket. Modern governments have acknowledged energy as a basic need and a vital input for economic growth and this realization has led many countries, especially developing ones, to establish energy pricing policies that benefit consumers at large and make energy affordable for all income groups. ${ }^{1}$ However, due to the rapid increase in oil prices internationally since 2003, large imbalances of payments and budget deficits have forced

\footnotetext{
* Lecturer, Government Degree College, Bakhshali, Mardan, and PhD candidate, Abdul Wali Khan University, Pakistan.

** $\mathrm{PhD}$ candidate, Pakistan Institute of Development Economics (PIDE), Islamabad, Pakistan. *** PhD candidate, Pakistan Institute of Development Economics (PIDE), Islamabad, Pakistan.

***** Associate Professor, Pakistan Institute of Development Economics (PIDE), Islamabad, Pakistan. ${ }^{1}$ There is a social motive behind the introduction of energy pricing policies by governments: to make energy affordable for low-income groups.
} 
many governments to adjust their pricing policies, with a cut in energy subsidies occurring across the global level.

Since energy pricing policies directly and indirectly affect households' real income (del Granado et al., 2012), ${ }^{2}$ governments tend to devise energy pricing policies - or may advance subsidies - that protect poor households from volatility in the energy cost of cooking, lighting and transportation. Nevertheless, subsidy-based energy pricing policies are often perceived as being inequitable and inefficient. In particular it is also presumed that subsidies crowd out high-priority government spending and encourage overconsumption (González, 2009; IEA et al., 2010).

Most of the benefit of subsidies is usually received by higher-income groups (Andriamihaja \& Vecchi, 2007; del Granado et al. 2012; Vagliasindi, 2012). González (2009) and del Granado et al. (2012) find that the benefit of subsidies on energy prices reaches only 60 percent of the population, of which high-income groups capture six times the benefit accruing to lowerincome groups. Additionally, the marginal social cost of subsidies on energy prices is higher than the benefit (Adagunodo, 2013). Consequently, the reduction or removal of subsidies saves public funds and can even improve the distribution of income in a society (Hartono \& Resosudarmo, 2006; Mourougane, 2010). ${ }^{3}$ Thus, it is necessary to apply effective and properly targeted price regulations, so that their proposed objectives are met (Frondel et al., 2010.

When these unfavorable attributes of subsidies on energy prices are accompanied by fiscal pressures, it leads to a change in energy pricing policies, mostly in the form of reduced or eliminated energy subsidies. However, even if empirical appraisals support the case for eliminating energy subsidies, there should be alternative policies that help limit the adverse impact on poor households (Gangopadhyay et al., 2005). Lowerincome households show less flexibility in adjusting to energy prices and consumption because they use energy only to meet their basic needs. Therefore, they face a higher welfare loss when subsidies on energy prices are removed.

\footnotetext{
2 The increase in real disposable income due to payment of lower prices by households for the consumption of energy products is termed the direct effect. Indirect effects occur in the payment of lower prices by households for other goods and services, which is reflected in the lower cost of energy-based production inputs.

${ }^{3}$ Mourougane (2010) confirms that, if energy subsidies were reduced by a quarter, this could generate an estimated USD 2 billion in savings per year (0.2 percent of GDP).
} 
The discussion above suggests that energy pricing policies and subsidies should be devised prudently. However, reforms to subsidies are usually difficult to implement due to rent seeking and the government's inability to convince citizens in this regard (Dansie et al., 2010; Albers \& Peeters, 2011). Since the early 2000s, the Government of Pakistan's energy pricing policy has allocated generous subsidies to the energy sector to protect its citizens from rising fuel costs, ${ }^{4}$ particularly for lower-income groups. Much of the lower-income population lives in rural areas and is close to the poverty line since it relies on farming and has no alternative resources or substitutes. Thus, a rise in energy prices is most likely to hurt rural consumers in Pakistan.

Despite the government's efforts to bring about changes in the energy pricing policy, wealthy and commercial consumers and some categories of industrial consumer enjoy the benefit of large subsidies. After entering into successive loan agreements with the IMF, the government has tried to reform its energy pricing policy and phase out energy subsidies gradually to create some fiscal space; however, it has had little success. In developing countries such as Pakistan, energy is considered a proximate factor in stimulating economic activity. Thus, any undesired change could affect people's wellbeing and economic growth. In this study, we assess the energy pricing policy in Pakistan and gauge whether potential reforms to energy subsidies would affect consumers' welfare. ${ }^{5}$

Our analysis is different from the existing literature on the association between economic growth and energy consumption in Pakistan (see Siddiqui, 2004), the causes of and solutions to the energy crisis (see Alahdad, 2012; Kessides, 2013), and energy demand and supply issues (see Hathaway et al., 2007; Burney \& Akhtar, 1990; Khan \& Ahmad, 2008). We focus on both the rural and urban regions, and check the robustness of our results with respect to differences in income. Using data from the Household Integrated Economic Survey (HIES), we employ the almost ideal demand system (AIDS), which is flexible enough to satisfy the axioms of choice and therefore produces reliable estimates.

\footnotetext{
${ }^{4}$ In the period 2004 to 2010, the Government of Pakistan extended 1.12 percent of GDP in the form of subsidies to the energy sector (Vagliasindi, 2012). Currently, it allocates more than Rs200 billion a year in the form of subsidies to the energy sector, much of which goes to the power sector. The total amount in subsidies extended by the government to the energy sector in the last five years was Rs 1,250 billion (Kessides, 2013).

${ }^{5}$ Recently, Aziz et al. (2016) have also probed the effect of higher energy prices on consumers' welfare in Pakistan.
} 
Our results confirm that there has been a consistent welfare loss to all consumers, with a decreasing trend due to the increase in energy prices. Additionally, the welfare loss to rural consumers is greater than the welfare loss to urban consumers. The rest of the study is organized as follows. Section 2 describes the data and methodological framework. Section 3 presents the empirical results of our analysis and Section 4 concludes the paper.

\section{Data and Methodology}

This section describes the data and the methodological framework.

\subsection{Data}

This study uses pooled data instead of cross-sectional or time series data. For assessing economic relationships, time series data is more suitable on theoretical grounds, but in practice it exhibits many problems, such as high correlation among the explanatory variables. Likewise, we are unable to estimate coefficients for prices using cross-sectional data because, for all consumers at any point in time, the price structure remains the same. To avoid these problems, we use pooled data which provides a large sample and yields sufficient degrees of freedom to obtain more reliable estimates.

The data is taken from multiple Household Integrated Economic Surveys (HIES) for rural and urban Pakistan for the period 1984/85 to 2011/12. The HIES is conducted by the Pakistan Bureau of Statistics and the dataset is not a panel since the same households are not re-surveyed in each wave. This dataset divides households into several income groups and provides information on their expenditure on various commodities. We use the data on nine goods: food and beverages; apparel, textiles and footwear; firewood; kerosene oil; gas; electricity, house rent and housing; transport and communications; and miscellaneous. ${ }^{6}$ Goods such as food and beverages, apparel, textiles and footwear, housing and miscellaneous are included to compare their prices and price elasticities with those of the energy products (electricity, gas, firewood and kerosene oil), and to

\footnotetext{
${ }^{6}$ Out of a total of nine goods, the energy goods (firewood, kerosene oil, gas and electricity) are considered at disaggregate level, while all other goods (food and beverages, apparel, textiles and footwear, transport and communications, house rent and housing) are considered at aggregate level. The goods included in miscellaneous are furniture and household equipment, education and recreation. Expenditure trends for urban and rural households on energy goods are given in Table A4 in the Appendix. Over the years, urban households have spent more on electricity, followed by gas and firewood, while rural households have spent more on firewood, followed by electricity and gas.
} 
determine their shares of the total expenditure of households in urban and rural Pakistan.

The data for rural and urban Pakistan is pooled for 14 time periods and 12 income groups for the years 1984/85, 1985/86, 1986/87, 1987/88, $1990 / 91,1992 / 93,1996 / 97$ and 1998/99, and for five income groups for the years 2001/02, 2004/05, 2005/06, 2007/08, 2010/11 and 2011/12. These income groups have been constructed by the Pakistan Bureau of Statistics for the HIES, according to the incomes of urban and rural households in Pakistan. Data on the consumer price index (CPI) and the prices of the nine goods used in this study is obtained from various issues of the Pakistan Economic Survey published by the Ministry of Finance, and from the Pakistan Energy Yearbook published by the Ministry of Petroleum and Natural Resources. All price indices are converted to the base year 2000/01.7

\subsection{Methodology}

This section discusses the methodology we use to study the impact of energy prices on household welfare in Pakistan. First, we use the AIDS model and its linear approximation (LA/AIDS) to estimate the required parameters of the household demand model. Next, we estimate the uncompensated price elasticities to determine whether the data is consistent with economic theory. Finally, we estimate the effects of changes in energy prices on the welfare of households in the form of compensating income variations.

\subsubsection{AIDS Model}

The AIDS was proposed as a new demand system by Deaton and Muellbauer (1980), and is considered a breakthrough in demand system generation. Alston and Chalfant (1993) comment that, in the relatively short time since AIDS was introduced, economists have adopted it to the extent that it appears to be the most popular demand system. It is appealing because it satisfies almost all the properties of a theoretical demand system and has a high level of flexibility. AIDS gives an arbitrary first-order approximation of any demand system and satisfies the axioms of choice. Without invoking linear parallel Engel curves, it aggregates cleanly over consumers. It has a functional form that is consistent with household budget data and its estimation is simple. It satisfies the restrictions of homogeneity

\footnotetext{
${ }^{7}$ See Tables A1 to A4 in the Appendix for descriptive statistics of the data.
} 
and symmetry through linear restrictions on the fixed parameters, and its linear approximated version avoids the need for nonlinear estimation.

The AIDS model has been used in the literature on the welfare impact of energy prices. Adagunodo (2013) employs an AIDS model to examine the effect of energy prices reform on consumer welfare in Nigeria. Aziz et al. (2016) use the same approach (LA/AIDS) while investigating the impact of energy prices on consumer welfare in Pakistan.

The system is based on an expenditure function of the form

$$
\ln n[M(p, u)]=(1-u) \ln [a(p)]+u \ln [b(p)]
$$

where

$$
\begin{aligned}
& \ln [a(p)]=a_{\circ}+\sum_{k} a_{k}\left[\ln \left(p_{k}\right)\right]+\frac{1}{2} \sum_{k} \sum_{j} \gamma_{k j} *\left[\ln \left(p_{k}\right) \ln \left(p_{j}\right)\right] \\
& \ln [b(p)]=\ln [a(p)]+\beta_{\circ} \prod_{k}\left[p_{k}\right]^{\beta_{k}}
\end{aligned}
$$

Substituting equations 2 and 3 into equation 1 yields

$$
\underset{u \beta_{\circ} \prod_{k}\left[p_{k}\right]^{\beta}}{\ln [M(p, u)]=a_{\circ}+\sum_{k} a_{k}\left[\ln \left(p_{k}\right)\right]+\frac{1}{2} \sum_{k} \sum_{j} \gamma_{k j} *\left[\ln \left(p_{k}\right) \ln \left(p_{j}\right)\right]+}
$$

The Marshallian demand function for any good $i$ is obtained in two steps. By taking the derivative of the expenditure function above with respect to $\ln \left(p_{i}\right)$ and applying Shepherd's lemma in the first step, the compensated demand function is obtained as an equation for the expenditure share of good $i$. We substitute in the resulting equation the indirect utility function in the second step, which can also be obtained by inverting the above expenditure function. The result is an expenditure share equation of the form

$$
s_{i}=a_{i}+\sum_{j} \gamma_{i j} \ln p_{j}+\beta_{i} \ln \left(\frac{M}{P}\right)
$$

where $\gamma_{i j}=\frac{1}{2}\left(\gamma_{i j} *+\gamma_{j i} *\right)$

In the above system, $s_{i}$ is the budget share of good $i, p_{i}$ is the price of good $i, M$ denotes total expenditure and $P$ is the price index. The parameters $a_{i}$ are the intercepts of the share equations while $\gamma_{i j}$ and $\beta_{i}$ represent 
parameters indicating the sensitivity of the budget shares to changes in prices and real income, respectively.

The price index $P$ is defined as:

$$
\ln P=a_{\circ}+\sum_{k} a_{k} \ln p_{k}+\frac{1}{2} \sum_{j} \sum_{k} \gamma_{k j} \ln p_{k} \ln p_{j}
$$

The demand functions given in equation (6) are nonlinear in parameters. The natural starting point for predictions using the AIDS model is that, in the absence of change in relative prices and real expenditure $(\mathrm{M} / \mathrm{P})$, the budget shares are constant; this is a simple interpretation of an AIDS. Changes in real expenditure work through the $\beta_{i}$ coefficient; changes in relative prices operate through $\gamma_{i j}$. Further, the $\beta_{i}^{\prime} s$ add up to 0 and are positive for luxuries and negative for necessities.

Abstracting from the theoretical properties of the expenditure functions, this model has no restrictions on the structural parameters. The restricted model can be used to examine some of the conclusions of demand theory by imposing special conditions on the parameters successively. Some restrictions are imposed on the parameters of equations 5 and 6 to enforce consistency with theory. These restrictions are summarized below:

$$
\begin{aligned}
& \sum_{i} a_{i}=1, \sum_{i} \gamma_{i j}=0, \sum_{i} \beta_{i}=0 \\
& \sum_{j} \gamma_{i j}=0 \\
& \gamma_{i j}=\gamma_{j i}
\end{aligned}
$$

Provided equations (7), (8) and (9) hold, equation (5) represents a system of demand functions that add up to total expenditure $\left(\sum s_{i}=1\right)$, and which satisfy Slutsky symmetry and are homogenous of degree zero in prices and total expenditure taken together. Equation (7) is the set of addingup restrictions, equation (8) is the restriction of homogeneity in prices, and equation (9) is the Slutsky symmetry condition. Simply put, equation (7) means that the budget shares should add up to unity.

Since the budget shares add up to unity, in equation (5) the parameters $a_{i}$ must also add up to unity, while the $\gamma_{i j}$ matrix and $\beta_{i}$ vector must add up to 0 in dimension $i$. The system must also be homogenous of degree zero in prices and total expenditure, which means that the unit values should double with the doubling of prices, while total expenditure and the budget shares remain unchanged. This will happen only when the $\gamma_{i j}$ rows 
add up to 0 in dimension $j$. The demand system is complete, as the addingup and homogeneity restrictions enable us to add another commodity defined as 'all other goods' as well as by deriving its own and crosselasticities from these restrictions. When $\gamma_{i j}=\gamma_{j i}$, then the substitution matrix of the demand system is symmetric. Symmetry restriction is commonly used in demand analysis to maintain theoretical consistency of the parameter estimates.

Equation (5) is very close to being linear, which is convenient from an econometric point of view. The system will become linear in parameters if $P$ is estimated separately. Equation (6) defines $P$ as a homogenous linear function of individual prices ensured by the restrictions on $a$ and $\gamma . P$ is defined as the approximate price index due to the relative collinearity of prices in practical situations.

As used by Stone:

$$
\ln P^{*}=\sum_{k}\left(s_{k} \ln p_{k}\right)
$$

This index is calculated directly before estimation so that equation (5) becomes

$$
s_{i}=a_{i}+\sum_{j} \gamma_{i j} \ln p_{j}+\beta_{i}\left(\frac{M}{P^{*}}\right)
$$

Equation (11) can be estimated easily and is known as an LA/AIDS model. In general, the relationship between AIDS parameters and LA/AIDS parameters in this form is not known; these are non-nested models. Stone's price index is a good proxy for the price index in equation (5). The estimates of the LA/AIDS model approach the estimates of the AIDS model except for the intercept term, when changes in price are proportional to one another. It is not known whether the theoretical properties of consumer theory are satisfied by the LA/AIDS model.

\subsubsection{Price Elasticities}

Price elasticity is a measure of the relationship between a change in the quantity demanded of a good due to a change in its own price or the price of another good. The uncompensated elasticities in terms of AIDS and LA/AIDS models can be defined as

$$
\eta_{i j}=\frac{d \ln Q_{i}}{d \ln P_{i}}=-\delta_{i j}+\frac{d \ln s_{i}}{d \ln P_{j}}=-\delta_{i j}+\left\{\gamma_{i j}-\beta_{i} \frac{d \ln P}{d \ln P_{j}}\right\} / s_{i}
$$


Holding total group expenditure and all other prices constant, these elasticities relate to allocations within the group. The term $\delta_{i j}$ is known as the Kronecker delta: it is equal to 1 if and only if $i=j$ and is equal to 0 if $i \neq$ $j$. For the correct expression of elasticity in the AIDS model, the term in equation (12), $\frac{d \ln P}{d \ln P_{j}}$, can be elaborated as $\frac{d \ln P}{d \ln P_{j}}=a_{i} \sum_{k} \gamma_{k j} \ln P_{k}$. Plugging this expression into equation 12 , the formula for elasticity becomes

$$
\eta_{i j}=-\delta_{i j}+\frac{\gamma_{i j}}{s_{i}}-\frac{\beta_{i} a_{i}}{s_{i}}-\frac{\beta_{i}}{s_{i}} \sum_{k} \gamma_{k j} \ln P_{k}
$$

This formula does not work for LA/AIDS as we use a different price index instead of the price index given in equation (6). The price index used in LA/AIDS is:

$$
\ln P^{*}=\sum_{k} s_{k} \ln P_{k}
$$

Stone's price index is differentiated with respect to the $j$ th commodity price to obtain the formula for price elasticity in the LA/AIDS model. The final expression obtained is:

$$
\eta_{i j}=-\delta_{i j}+\frac{\gamma_{i j}}{s_{j}}-\frac{\beta_{i} s_{j}}{s_{i}}-\beta_{i} / s_{i}\left[\sum_{k} s_{k} \ln P_{k}\left(\eta_{k j}+\delta_{k j}\right)\right]
$$

which can be expressed in matrix form as

$$
E=A-(B C)(E+I)
$$

Its typical elements are $a_{i j}=-\delta_{i j}\left(\frac{\gamma_{i j}}{s_{j}}\right)-\beta_{i}\left(\frac{s_{j}}{s_{i}}\right)$ in $\mathrm{A}$ (an $n \times n$ matrix); $b_{i}=\left(\beta_{i} / s_{i}\right)$ in $\mathrm{B}($ an $n \times 1$ vector $) ; c_{j}=s_{j} \ln P_{j}$ in $\mathrm{C}$ (an $n \times 1$ vector); and $\eta_{i j}=-\delta_{i j}+\gamma_{i j} / s_{j}-\beta_{i} s_{j} / s_{i}-\frac{\beta_{i}}{s_{i}}\left[\sum_{k} s_{k} \ln P_{k}\left(\eta_{k j}+\delta_{k j}\right)\right]$ in $\mathrm{E}($ an $n \times n$ matrix). Solving for elasticities $\left[\eta_{i j}\right]$ yields, after some simplifications,

$$
E=[B C+1]^{-1}[A+I]-I
$$

where $I$ is the identity matrix.

The formula used to calculate income elasticities is

$$
N=(I+B C)^{-1} B+i
$$

where $N(n \times 1)$ is the expenditure/income elasticities vector and $i$ is an $n$ unit vector. 


\subsubsection{Welfare Effects of Energy Price Changes}

The welfare effects of energy price changes can be analyzed using a specific measure of welfare for consumers, and the actual and hypothetically specified energy prices. One approach to setting these hypothetical energy prices, which is often adopted in the literature, is to consider the existing energy subsidies and then gauge what impact their removal will have on consumers. This approach is appropriate when analyzing the effect of removing one specific structure of energy subsidies. However, in using this approach, it becomes difficult to analyze the cumulative effect of removing all distortions that exist due to the introduction of taxes and subsidies applied in the past.

An alternative approach, which we follow here, is to set energy prices at some benchmark level and then compare the effect of changing the prices from the actual to the benchmark levels. To apply this approach, we consider the compound inflation rate of each energy category over a given period and then replace this rate with the CPI inflation rate for the same period. The benchmark energy prices for the current period are then computed by applying the CPI inflation rate over the period under consideration. The period for the present analysis is the latest year of data, $2011 / 12$. To compute the benchmark energy prices, we consider the following periods: $1992 / 93$ to $2011 / 12$, 1996/97 to $2011 / 12,2001 / 02$ to $2011 / 12$, and $2007 / 08$ to $2011 / 12$

The next question is how to measure welfare. Since consumers' utility itself is not measurable, the effect of price changes on the welfare of a consumer can only be measured in monetary terms. A simple way to measure the welfare effect of price changes is to compute the effect of price changes on the total expenditure incurred when purchasing a given basket. The advantage of this measure is that it is simple to calculate, but it is a poor measure of the true welfare effect as it assumes that consumers' choices do not respond to price changes at all. The alternative approach, which involves the concept of consumer surplus and allows for changes in demand in response to price changes, is obviously preferable.

The typical measure of consumer surplus is based on the assumptions that utility is measurable cardinally and that the marginal utility of money is constant (Winch, 1971). Alternative measures of consumer surplus have been proposed that do not require these two assumptions. Winch (1971) explains four alternative measures of consumer surplus: compensating variation $(\mathrm{CV})$, equivalent variation, compensating 
surplus and equivalent surplus. Although any one of these can be used to estimate the effects of energy price changes on the welfare of consumers, the most suitable one, as will become obvious in the following analysis, is CV, which measures the increase in income that compensates for the price increase, or the decrease in income that compensates for the price decrease, as may be the case. Studies such as Niimi (2005), Nicita (2004), and Friedman and Levinsohn (2002) have also used the CV technique to measure changes in consumer welfare.

Consider the level of utility at the initially given prices. Inverting the expenditure function (IUF) under AIDS (equation 1) for utility, we obtain the following indirect utility function:

$$
U=\frac{\log (M)-\log [a(P)]}{\log [b(P)]-\log [a(P)]}
$$

Substituting for the functions $\log [a(P)]$ and $\log [b(P)]$ from equations (2) and (3), respectively, we obtain:

$$
U=\frac{\log (M)-a_{0}-\sum_{k} a_{k} \log \left(p_{k}\right)-\frac{1}{2} \sum_{k} \sum_{j} \gamma_{k j}^{*} \log \left(p_{k}\right) \log \left(p_{j}\right)}{\beta_{0} \Pi_{k}\left(p_{k}\right)^{\beta_{k}}}
$$

Let observed prices be denoted by $P_{k}^{0}$ and proposed prices by $P_{k}^{1}$. Initial income or total expenditure is denoted by $M^{0}$. The first step is to compute the value of utility using the IUF (19), that is:

$$
U^{0}=\frac{\log \left(M^{0}\right)-a_{0}-\sum_{k} a_{k} \log \left(p_{k}^{0}\right)-\frac{1}{2} \sum_{k} \sum_{j} \gamma_{k j}^{*} \log \left(p_{k}^{0}\right) \log \left(p_{j}^{0}\right)}{\beta_{0} \prod_{k}\left(p_{k}^{0}\right)^{\beta_{k}}}
$$

The value of utility obtained above is used to compute the value of the log of expenditure at the new prices using the expenditure function equation (1) as follows:

$$
\log \left(M^{1}\right)=a_{0}+\sum_{k} a_{k} \log \left(p_{k}^{1}\right)+\frac{1}{2} \sum_{k} \sum_{j} \gamma_{k j}^{*} \log \left(p_{k}^{1}\right) \log \left(p_{j}^{1}\right)+U^{0} \beta_{0} \Pi_{k}\left(p_{k}^{1}\right)^{\beta_{k}}
$$

Substituting for $U^{0}$, we obtain: 


$$
\begin{aligned}
\log \left(M^{1}\right) & =a_{0}+\sum_{k} a_{k} \log \left(p_{k}^{1}\right)+\frac{1}{2} \sum_{k} \sum_{j} \gamma_{k j}^{*} \log \left(p_{k}^{1}\right) \log \left(p_{j}^{1}\right) \\
& +\left[\log \left(M^{0}\right)-a_{0}-\sum_{k} a_{k} \log \left(p_{k}^{0}\right)-\frac{1}{2} \sum_{k} \sum_{j} \gamma_{k j}^{*} \log \left(p_{k}^{0}\right) \log \left(p_{j}^{0}\right)\right] \prod_{k}\left(\frac{p_{k}^{1}}{p_{k}^{0}}\right)^{\beta_{k}}
\end{aligned}
$$

Note, that in the AIDS estimation, we estimate only the share equations but we cannot estimate the expenditure function or the IUF. This means that all the parameters of the system except $\beta^{0}$ are estimated. However, as we can see from equation (23), this parameter drops out when computing the expenditure at new prices but at an old level of utility. This means that, despite not being able to estimate $\beta^{0}$, we are able to make all the necessary computations for our welfare analysis.

Finally, given the initial total expenditure $M^{0}$ and the computed new expenditure to retain the initial level of expenditure $M^{1}$, we obtain the percentage $\mathrm{CV}$ when moving from old prices to new prices as follows:

$$
C V=\frac{M^{1}-M^{0}}{M^{0}} 100
$$

In applying this procedure, we consider a representative consumer whose total expenditure (representing income) is equal to the mean per capita total expenditure obtained from the entire sample. The actual prices are set equal to the prices prevailing in the current year 2011/12, and the benchmark prices are obtained by applying the CPI inflation rate to the prices of energy categories over some period. If the benchmark prices of energy categories are less than the observed prices as expected, then the CV given above will be negative, indicating that the representative consumer would have incurred lower expenditure to maintain his or her existing level of wellbeing had the energy prices increased at the rate of CPI inflation rather than the observed inflation rate.

\section{Empirical Results}

We have estimated both the linear and nonlinear versions of the AIDS for rural and urban Pakistan separately. However, we rely on the results of the NL/AIDS model, which are more promising and significant than those of the linear AIDS model in terms of direction and magnitude. Similar to our analysis, Zhou (2015) estimates both the linear and nonlinear versions of the AIDS model. The author compares the results of the NL/AIDS model with those of the linear AIDS model and concludes that the former are more reasonable and in line with economic theory. Hence, the 
NL/AIDS model is preferable to the linear one. Therefore, we focus on the results of the NL/ AIDS. The results of the linear AIDS are given in Tables A5-A8 in the Appendix.

The NL/AIDS for both rural and urban Pakistan is estimated using a seemingly unrelated regression procedure by imposing certain conditions on the parameters, such as adding up, homogeneity and symmetry. Tables 1 and 2 give estimates of the NL/AIDS model for rural and urban Pakistan, respectively. In the case of rural Pakistan, the intercept terms for food and beverages, apparel, textiles and footwear, firewood, kerosene oil, and house rent and housing are positive with reasonable magnitudes and are highly statistically significant, which indicates that significant proportions of expenditure on these commodities are independent of changes in price and incomes. 


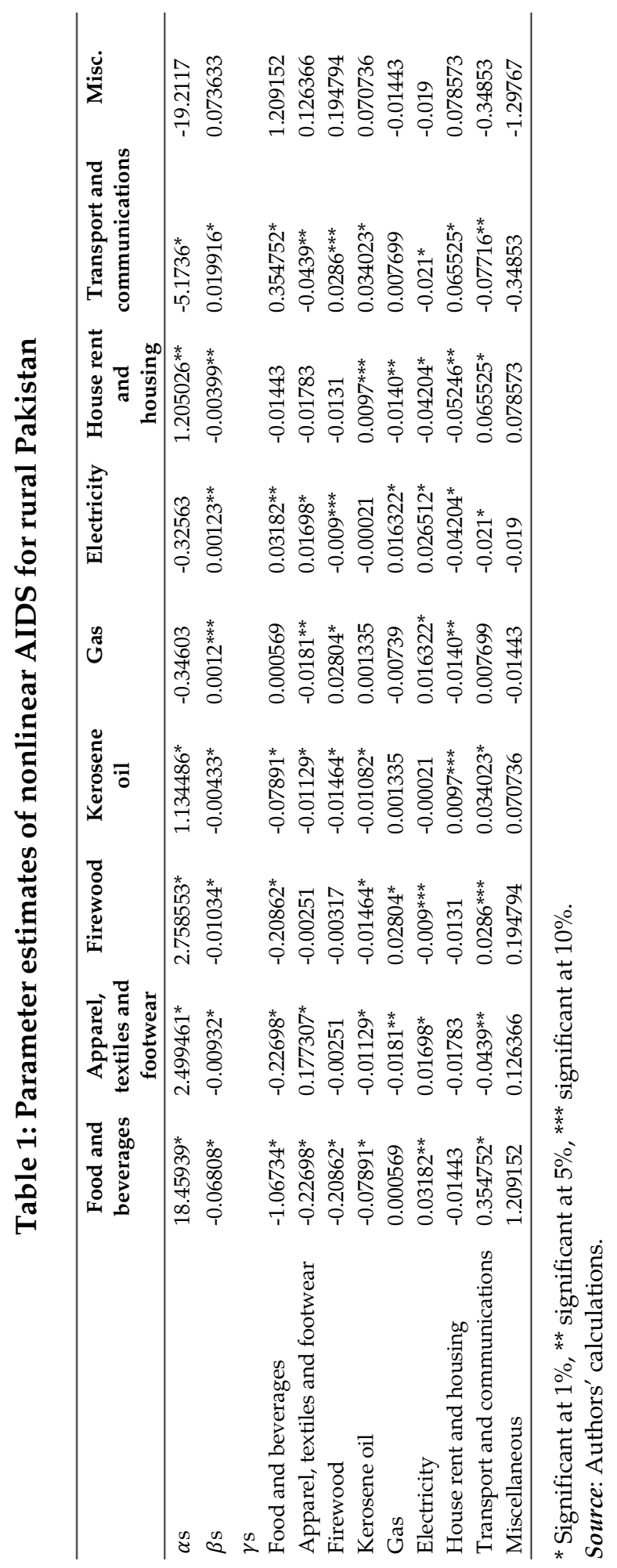




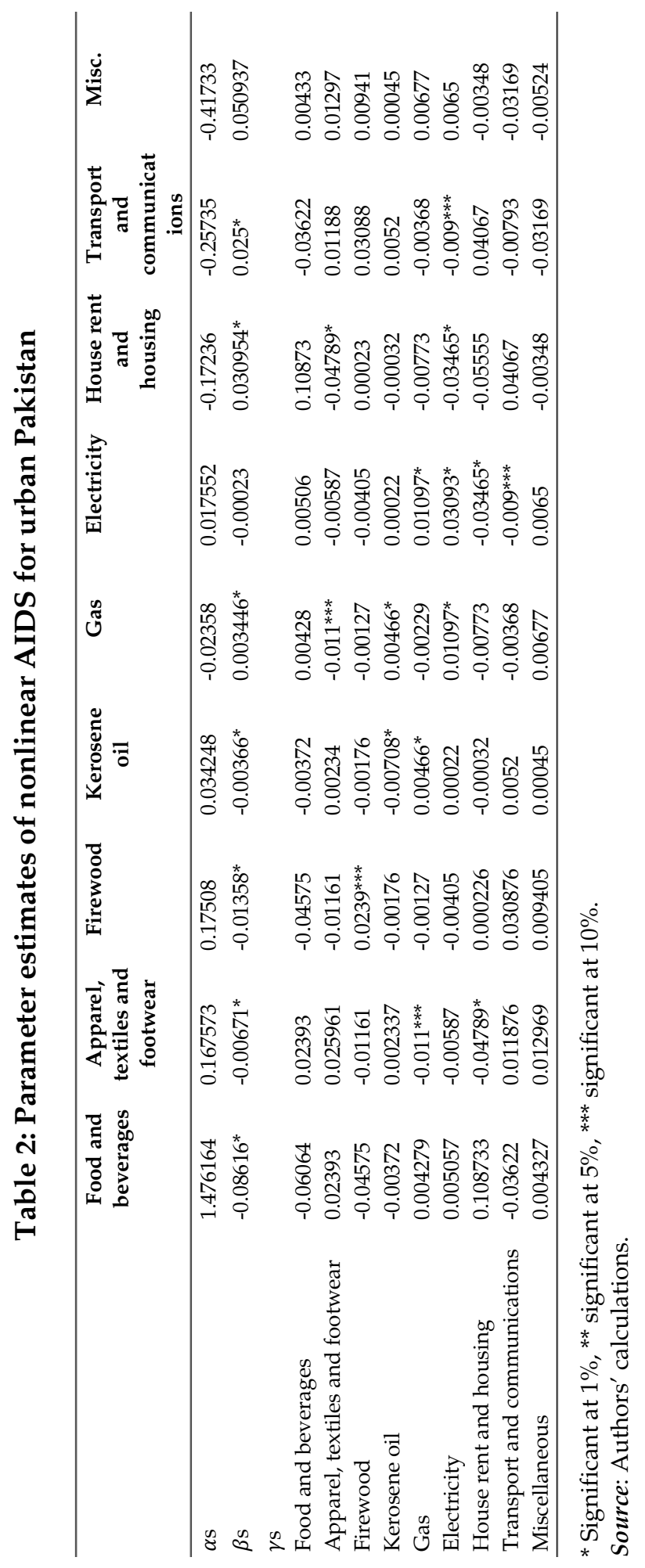


The intercept term for transport and communications is significant but negative for rural Pakistan, which indicates that the share of transport and communications will be negative if price and income effects are ignored. In the case of urban Pakistan, the intercept terms are positive for food and beverages, apparel, textiles and footwear, firewood, kerosene oil, and electricity, and negative for gas, house rent and housing, and transport and communications.

The nature of a good $i$ as a luxury or necessity is determined by the parameter $\beta_{i}{ }^{8}$ The results for rural Pakistan show that the $\beta_{i} s$ for food and beverages, apparel, textiles and footwear, firewood, kerosene oil and house rent and housing are negative and statistically significant, indicating that these are necessities in rural Pakistan. The $\beta_{i} s$ for gas, electricity and transport and communications are positive and statistically significant, indicating that these are luxuries in rural Pakistan. For urban Pakistan, food and beverages, apparel, textiles and footwear, firewood, kerosene oil and electricity are classified as necessities, as indicated by the negative sign of the corresponding $\beta_{i} S$, while gas, house rent and housing, and transport and communications are luxuries.

The change in the share of the $i$ th good due to a 1 percent change in its own price or the price of any other good, with constant expenditure, is measured by $\gamma_{i j}$. The price elasticities for rural and urban Pakistan are shown in Tables 3 and 4, respectively. All the own-price elasticities are negative both for rural and urban Pakistan. For rural Pakistan, the own-price elasticities of firewood, kerosene oil, gas and electricity are $-0.12,-2.06,-4.56$ and -0.68 , respectively, which means that there will be a $0.12,2.06,4.56$ and 0.68 percent decrease in the consumption of these commodities in rural Pakistan if there is a 1 percent increase in their prices. The own-price elasticities of firewood, kerosene oil, gas and electricity in urban Pakistan are $-0.87,-2.22,-1.19$ and -0.05 , which means that, with a 1 percent increase in the prices of these commodities, the decrease in their quantity demanded will be $0.87,2.22,1.19$ and 0.05 percent, respectively.

\footnotetext{
${ }^{8}$ If $\beta_{i}>0$, good $i$ is a luxury, meaning that the expenditure on good $i$ will increase with an increase in income. If $\beta_{i}<0$, good $i$ is a necessity, meaning that the expenditure on good $i$ will decrease with an increase in income.
} 

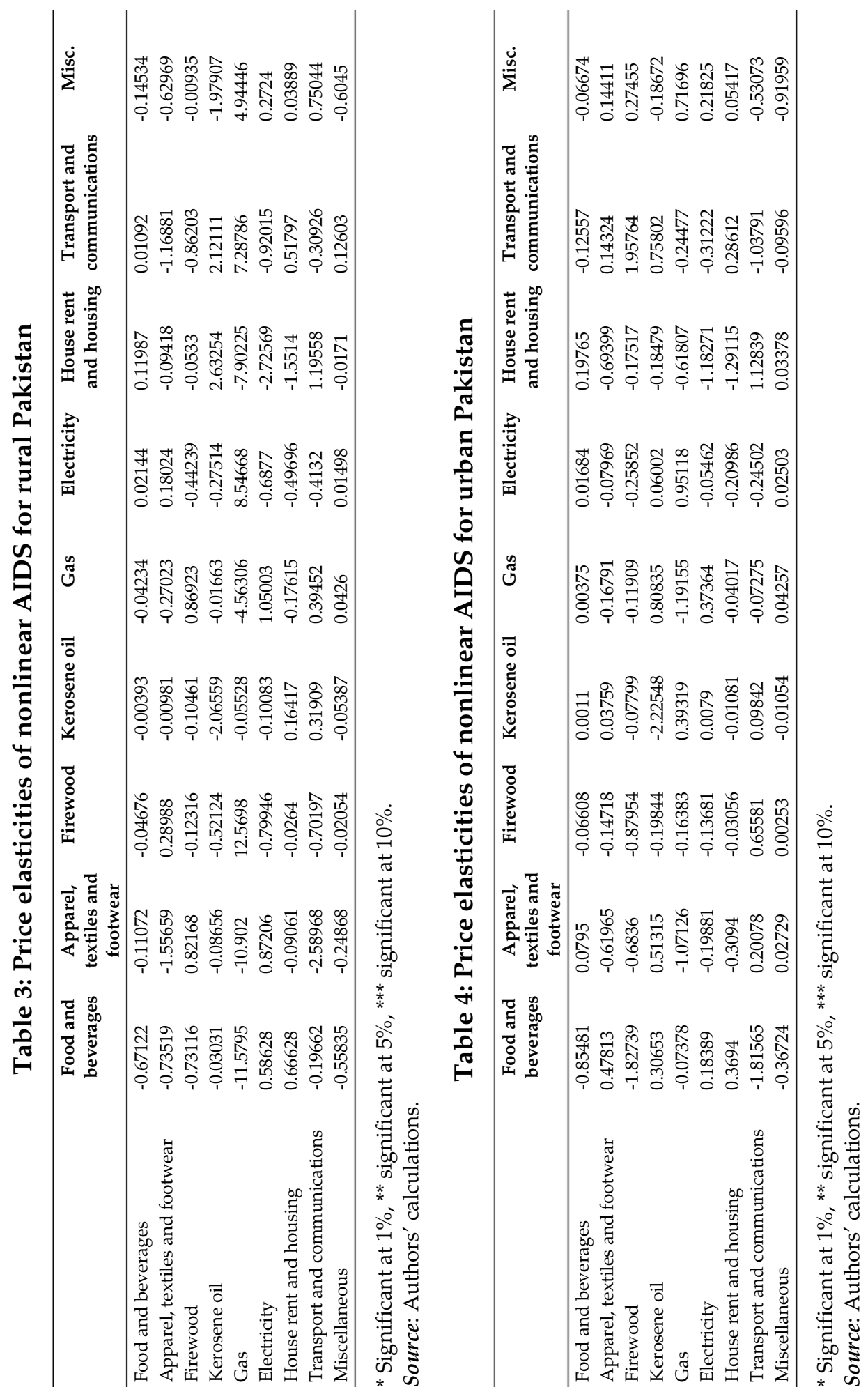
The estimates of cross-price elasticities yield mixed results. The cross-price elasticities with a positive sign show that these goods are substitutes, while a negative sign shows that these goods are complements. The cross-price elasticities show that firewood and gas in the rural areas, and gas and electricity are substitutes, while kerosene oil and firewood are complements.

The increase in price of energy products (electricity, gas, kerosene oil and firewood) in the last three decades is more than the increase in the general CPI, as shown in Table 5. Using the CPI and prices of energy products (electricity, gas, kerosene oil and firewood) from 1984/85 to $2011 / 12$, the actual prices of energy products are set equal to the prices prevailing in the current year 2011/12, and the benchmark prices are obtained by applying the CPI inflation rate to the prices of fuel categories over the sample period.

\section{Table 5: Percentage inflation rates of CPI and price indices of energy products}

\begin{tabular}{lccccc}
\hline Year & CPI & $\begin{array}{c}\text { Price of } \\
\text { firewood }\end{array}$ & $\begin{array}{c}\text { Price of } \\
\text { kerosene oil }\end{array}$ & Price of gas & $\begin{array}{c}\text { Price of } \\
\text { electricity }\end{array}$ \\
\hline $1984 / 85$ & 8.652953 & 10.104751 & 16.318860 & 12.504619 & 11.235044 \\
$1985 / 86$ & 8.821785 & 10.447674 & 16.585162 & 13.015612 & 11.449170 \\
$1986 / 87$ & 9.036121 & 10.683708 & 17.577179 & 13.536617 & 11.754812 \\
$1987 / 88$ & 9.151905 & 10.852841 & 18.400168 & 13.721335 & 12.076501 \\
$1990 / 91$ & 9.079234 & 10.924647 & 19.314973 & 13.733739 & 11.867736 \\
$1992 / 93$ & 9.039529 & 10.858473 & 16.289658 & 14.491710 & 12.357463 \\
$1996 / 97$ & 8.336276 & 11.281809 & 16.462110 & 15.057746 & 11.611556 \\
$1998 / 99$ & 8.579637 & 12.311093 & 18.358637 & 16.957451 & 10.337948 \\
$2001 / 02$ & 10.425225 & 15.557101 & 20.065572 & 17.809887 & 11.951588 \\
$2004 / 05$ & 11.995142 & 18.333562 & 20.087507 & 17.060139 & 10.599570 \\
$2005 / 06$ & 12.689255 & 17.714517 & 19.395989 & 16.976079 & 11.802355 \\
$2007 / 08$ & 14.127356 & 18.938217 & 24.640533 & 24.616021 & 16.868148 \\
$2010 / 11$ & 10.364797 & 24.683169 & 23.515551 & 20.069929 & 13.587100 \\
\hline
\end{tabular}

Source: Authors' calculations.

If the benchmark prices of fuel categories are less than the observed prices, then the $\mathrm{CV}$ will be negative, indicating that the representative consumer will have incurred less expenditure to maintain the existing level of wellbeing had the fuel prices increased at the rate of CPI inflation rather than the observed inflation rate. Since energy prices have increased at a higher rate than the CPI inflation rate and consumers are incurring more expenditure, representing a welfare loss for consumers. 
Table 6 shows the welfare gain or loss for consumers in rural and urban Pakistan due to energy pricing policies. Our results show that both rural and urban consumers have been paying higher prices for energy products (electricity, gas, kerosene oil and firewood) than the benchmark level of prices, incurring high expenditures in all the years from 1984 to 2011. This represents a consistent welfare loss for all consumers. Rural consumers have been paying far higher prices than the benchmark level of prices in the past: their welfare loss was very high in 1984 (13.17 percent), which gradually decreased over time to 11.01 percent in 1999 and to 2.58 percent in 2011.

Table 6: Welfare gain and loss for rural and urban Pakistan

\begin{tabular}{ccc}
\hline $\begin{array}{c}\text { Energy inflation set equal } \\
\text { to CPI inflation till 2011/12 } \\
\text { from the year }\end{array}$ & $\begin{array}{c}\text { Percentage change in } \\
\text { expenditure in rural } \\
\text { Pakistan }\end{array}$ & $\begin{array}{c}\text { Percentage change in } \\
\text { expenditure in urban } \\
\text { Pakistan }\end{array}$ \\
\hline New 1984/85 & -13.1769 & -3.31152 \\
New 1985/86 & -13.2692 & -3.38778 \\
New 1986/87 & -13.4739 & -3.36409 \\
New 1987/88 & -13.7403 & -3.35116 \\
New 1990/91 & -13.322 & -2.84972 \\
New 1992/93 & -9.87021 & -3.27489 \\
New 1996/97 & -10.5028 & -3.0106 \\
New 1998/99 & -11.0103 & -2.36629 \\
New 2001/02 & -10.4125 & -1.76838 \\
New 2004/05 & -8.25478 & -0.54071 \\
New 2005/06 & -5.82269 & -0.42829 \\
New 2007/08 & -4.11864 & -0.96624 \\
New 2010/11 & -2.58153 & -0.36017 \\
\hline
\end{tabular}

Source: Authors' calculations.

Consumers in urban Pakistan have also been paying higher prices than the benchmark level of prices in the past, but their welfare loss is smaller than that of rural consumers. The welfare loss for urban consumers was 3.31 percent in 1984, which gradually decreased over time to 2.36 percent in 1999 and to 0.36 percent in 2011. The welfare loss for both rural and urban consumers has decreased over time from 1984 to 2011, since the observed prices have approached the benchmark level of prices in all these years. For this reason, consumers' expenditure on energy products (electricity, gas, kerosene oil and firewood) has gradually decreased, leading to a reduction in the welfare loss for both rural and urban consumers. These results are consistent with Aziz et al. (2016), who conclude that CV is positive (and consumer welfare falls) due to a rise in energy prices, especially in inflationary conditions. 
In both urban and rural Pakistan, firewood has a negative and inelastic own-price elasticity. The findings suggest that its demand is less responsive to changes in its own price in both areas. This result is consistent (in direction and almost in magnitude) with Kidane (1991), who finds an inelastic demand for firewood in Ethiopia. Additionally, electricity and gas are essential energy sources in Pakistan. According to our results, electricity and gas are necessities in Pakistan, echoing the results of Akmal (2002) and Khan and Ahmad (2008).

That the price elasticity of demand for electricity is relatively less responsive to own price is in line with Siddiqui (1999) and Khan and Ahmad (2008), but different from Chaudhry et al. (2012). We find that the demand for gas responds considerably to changes in its own price, which is not consistent with Siddiqui (1999) and Khan and Ahmad (2008). It is important to note that the responsiveness of demand for energy products is, in most cases similar to Siddiqui (1999). Our results are also consistent with Davoodi and Salem (2007), Asghar et al. (2010), Nikban and Nakhaie (2011), Araghi and Barkhordari (2012), Ahmadian et al. (2007), and Huang and Huang (2012).

\section{Conclusion}

This study has analyzed the welfare of households corresponding to changes in energy prices. The study uses data from the HIES for the period 1984/85 to 2011/12 and employs an AIDS model. The welfare analysis shows that the increase in prices of energy has been greater than the increase in the general CPI over this period. Therefore, consumers have been paying more for energy products, incurring a higher expenditure in all the years from 1984 to 2011, with a consistent welfare loss for all consumers. However, over time from 1984 to 2011, the welfare loss of consumers has decreased because of the decreasing gap between energy price rises and the CPI. Furthermore, the welfare loss to rural consumers is higher than that of urban consumers, due to the rapid and intensive increase in the prices of firewood and kerosene oil compared to the increase in prices of electricity and gas. In terms of policy implications, if an energy policy leads to an increase in the price of energy which is greater than the CPI, consumers will incur greater energy expenditure and suffer from higher welfare losses. 


\section{References}

Adagunodo, M. (2013). Petroleum products pricing reform in Nigeria: Welfare analysis from household budget survey. International Journal of Energy Economics and Policy, 3(4), 459-472.

Ahmadian, M., Chitnis, M., \& Hunt, L. C. (2007). Gasoline demand, pricing policy and social welfare in the Islamic Republic of Iran. OPEC Review, 31(2), 105-124.

Akmal, M. (2002, February). The structure of consumer energy demand in Australia: An application of a dynamic almost ideal demand system. Paper presented at the $46^{\text {th }}$ Conference of the Australian Agricultural and Resource Economics Society, Canberra.

Alahdad, Z. (2012). Pakistan's energy sector: From crisis to crisis - Breaking the chain. Islamabad: Pakistan Institute of Development Economics.

Albers, R., \& Peeters, M. (2011). Food and energy prices, government subsidies and fiscal balances in South Mediterranean countries (Economic Paper No. 437). Brussels: European Commission.

Alston, J. M., \& Chalfant, J. A. (1993). The silence of the lambdas: A test of the almost ideal and Rotterdam models. American Journal of Agricultural Economics, 75(2), 304-313.

Andriamihaja, N. A., \& Vecchi, G. (2007). An evaluation of the welfare impact of higher energy prices in Madagascar (Africa Region Working Paper No. 106). Washington, DC: World Bank.

Araghi, M. K., \& Barkhordari, S. (2012). An evaluation of the welfare effects of reducing energy subsides in Iran. Energy Policy, 47, 398-404.

Aziz, S., Yaseen, M. R., \& Anwar, S. (2016). Impact of rising energy prices on consumer's welfare: A case study of Pakistan. Pakistan Development Review, 55(4), 605-618.

Burney, N. A., \& Akhtar, N. (1990). Fuel demand elasticities in Pakistan: An analysis of households' expenditure on fuels using micro data. Pakistan Development Review, 29(2), 155-174.

Chaudhry, I. S., Safdar, N., \& Farooq, F. (2012). Energy consumption and economic growth: Empirical evidence from Pakistan. Pakistan Journal of Social Sciences, 32(2), 371-382. 
Dansie, G., Lanteigne, M., \& Overland, I. (2010). Reducing energy subsidies in China, India and Russia: Dilemmas for decision makers. Sustainability, 2(2), 475-493.

Davoodi, A., \& Salem, J. (2007). The effect of increase in petroleum price on welfare of various income groups in Persian. Economic Researches, $23,15-48$.

Deaton, A., \& Muellbauer, J. (1980). Economics and consumer behavior. Cambridge: Cambridge University Press.

del Granado, F. J. A., Coady, D., \& Gillingham, R. (2012). The unequal benefits of fuel subsidies: A review of evidence for developing countries. World Development, 40(11), 2234-2248.

Friedman, J., \& Levinsohn, J. (2002). The distributional impacts of Indonesia's financial crisis on household welfare: A 'rapid response' methodology. World Bank Economic Review, 16(3), 397423.

Frondel, M., Ritter, N., Schmidt, C. M., \& Vance, C. (2010). Economic impacts from the promotion of renewable energy technologies: The German experience. Energy Policy, 38(8), 4048-4056.

Gangopadhyay, S., Ramaswami, B., \& Wadhwa, W. (2005). Reducing subsidies on household fuels in India: How will it affect the poor? Energy Policy, 33(18), 2326-2336.

González, A. D. (2009). Energy subsidies in Argentina lead to inequalities and low thermal efficiency. Energies, 2(3), 769-788.

Hartono, D., \& Resosudarmo, B. P. (2006). The economy-wide impact of fuel oil, gas and electricity pricing and subsidy policies as well as their consumption improvement efficiency in Indonesia (Working Paper No. 200611). Bandung, Indonesia: Padjadjaran University.

Hathaway, R. M., Muchhala, B., \& Kugelman, M. (Eds.). (2007). Fueling the future: Meeting Pakistan's energy needs in the 21st century. Washington, DC: Woodrow Wilson International Center for Scholars.

Huang, K. S., \& Huang, S. W. (2012). Consumer welfare effects of increased food and energy prices. Applied Economics, 44(19), 2527-2536. 
IEA, OPEC, OECD and World Bank. (2010). Analysis of the scope of energy subsidies and suggestions for the G-20 initiative. Prepared for submission to G-20 Summit Meeting, Toronto.

Kessides, I. N. (2013). Chaos in power: Pakistan's electricity crisis. Energy Policy, 55, 271-285.

Khan, M. A., \& Ahmad, U. (2008). Energy demand in Pakistan: A disaggregate analysis. Pakistan Development Review, 47(4), 437-455.

Kidane, A. (1991). Demand for energy in rural and urban centers of Ethiopia: An econometric analysis. Energy Economics, 13(2), 130134.

Mourougane, A. (2010). Phasing out energy subsidies in Indonesia (Economics Department Working Paper No. 808). Paris: OECD.

Nicita, A. (2004). Efficiency and equity of a marginal tax reform: Income, quality and price elasticities for Mexico (Working Paper No. 3266). Washington, DC: World Bank.

Niimi, Y. (2005). An analysis of household responses to price shocks in Vietnam: Can unit values substitute for market prices? (PRUS Working Paper No. 30). Falmer: University of Sussex .

Nikban, A., \& Nakhaie, H. (2011). Evaluation of consumers' welfare costs due to rise of energy carriers prices. In International Proceedings of Economics Development and Research (vol. 12, pp. 523-526). Singapore: IACSIT Press.

Siddiqui, R. (1999). Demand for energy and the revenue impact of changes in energy prices (Research Report No. 174). Islamabad: Pakistan Institute of Development Economics.

Vagliasindi, M. (2012). Implementing energy subsidy reforms: An overview of the key issues (Working Paper No. 6122). Washington, DC: World Bank.

Zhou, X. (2015). Using almost ideal demand system to analyze demand for shrimp in US food market. International Journal of Food and Agricultural Economics, 3(3), 1-16. 
Appendix

Table A1: Expenditure shares, by commodity group in urban Pakistan

\begin{tabular}{|c|c|c|c|c|c|c|c|c|c|c|}
\hline Year & 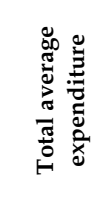 & 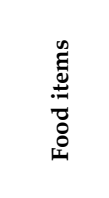 & 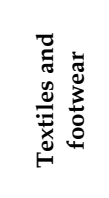 & 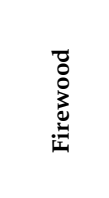 & 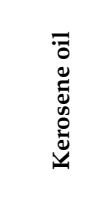 & 心 & 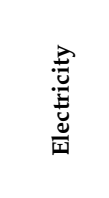 & 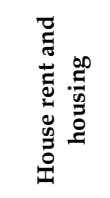 & 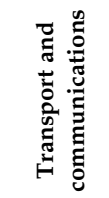 & $\underset{⿱ 乛 龰}{\dot{n}}$ \\
\hline $1984 / 85$ & 2305.66 & 0.432042 & 0.066814 & 0.009643 & 0.005951 & 0.009091 & 0.016845 & 0.172801 & 0.060542 & 0.22626 \\
\hline $1985 / 86$ & 2292.46 & 0.420420 & 0.068933 & 0.010602 & 0.006179 & 0.009977 & 0.017624 & 0.178550 & 0.059756 & 0.22795 \\
\hline $1986 / 87$ & 2354.61 & 0.415853 & 0.068166 & 0.010372 & 0.006074 & 0.008768 & 0.018266 & 0.181563 & 0.058254 & 0.23268 \\
\hline $1987 / 88$ & 2390.12 & 0.415902 & 0.068722 & 0.010247 & 0.005989 & 0.009482 & 0.020279 & 0.194371 & 0.041105 & 0.23389 \\
\hline $1990 / 91$ & 3978.09 & 0.409995 & 0.068922 & 0.012187 & 0.006334 & 0.009191 & 0.021991 & 0.183779 & 0.047012 & 0.24058 \\
\hline $1992 / 93$ & 3978.09 & 0.443405 & 0.078406 & 0.008867 & 0.005420 & 0.012150 & 0.025016 & 0.183779 & 0.047012 & 0.19594 \\
\hline $1996 / 97$ & 4452.18 & 0.463572 & 0.081022 & 0.011076 & 0.004648 & 0.014434 & 0.031571 & 0.176685 & 0.037529 & 0.17945 \\
\hline $1998 / 99$ & 4773 & 0.480010 & 0.078357 & 0.010518 & 0.004125 & 0.016244 & 0.037669 & 0.171266 & 0.027705 & 0.17410 \\
\hline $2001 / 02$ & 7378.2 & 0.443170 & 0.072104 & 0.007548 & 0.001910 & 0.019386 & 0.047039 & 0.191699 & 0.037264 & 0.17987 \\
\hline 2004/05 & 9448 & 0.438378 & 0.056710 & 0.009537 & 0.000924 & 0.017547 & 0.047635 & 0.179487 & 0.050833 & 0.19894 \\
\hline $2005 / 06$ & 11004 & 0.390393 & 0.052540 & 0.008048 & 0.000713 & 0.017633 & 0.046303 & 0.193788 & 0.061680 & 0.22889 \\
\hline $2007 / 08$ & 12771 & 0.418750 & 0.051514 & 0.007590 & 0.000292 & 0.016739 & 0.044215 & 0.197037 & 0.057019 & 0.20684 \\
\hline $2010 / 11$ & 16603.77 & 0.452817 & 0.049650 & 0.005858 & 0.000143 & 0.014121 & 0.049403 & 0.186198 & 0.059790 & 0.18201 \\
\hline $2011 / 12$ & 23041 & 0.422557 & 0.054277 & 0.004895 & $\begin{array}{l}7.2261 \mathrm{E}- \\
05\end{array}$ & 0.014006 & 0.049465 & 0.177045 & 0.062106 & 0.21557 \\
\hline
\end{tabular}

\section{Table A2: Expenditure shares, by commodity group in rural Pakistan}

\begin{tabular}{|c|c|c|c|c|c|c|c|c|c|c|}
\hline Year & 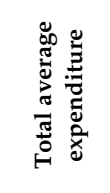 & 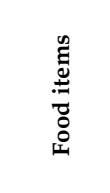 & 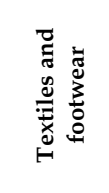 & 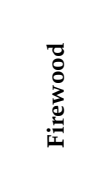 & $\begin{array}{l}\overline{0} \\
0 \\
0 \\
0 \\
0 \\
0 \\
0 \\
0\end{array}$ & తే & 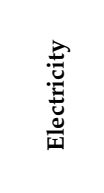 & 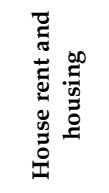 & 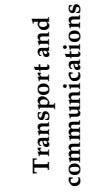 & $\stackrel{\dot{p}}{\stackrel{0}{\Sigma}}$ \\
\hline $1984 / 85$ & 2156.76 & 0.460434 & 0.072497 & 0.025750 & 0.005698 & 0.000580 & 0.005006 & 0.083533 & 0.049673 & 0.296828 \\
\hline $1985 / 86$ & 2091.61 & 0.481964 & 0.075430 & 0.026746 & 0.006286 & 0.000425 & 0.005247 & 0.078319 & 0.049927 & 0.275656 \\
\hline $1986 / 87$ & 2231.01 & 0.469619 & 0.073456 & 0.026673 & 0.005358 & 0.000628 & 0.007244 & 0.081872 & 0.045297 & 0.289854 \\
\hline $1987 / 88$ & 2332.24 & 0.472918 & 0.077288 & 0.026249 & 0.005471 & 0.000881 & 0.006978 & 0.081758 & 0.041321 & 0.287136 \\
\hline $1990 / 91$ & 3611.72 & 0.438219 & 0.069622 & 0.020666 & 0.005079 & 0.001194 & 0.010207 & 0.086486 & 0.033391 & 0.335137 \\
\hline $1992 / 93$ & 3611.73 & 0.508621 & 0.088021 & 0.026660 & 0.006730 & 0.001371 & 0.011388 & 0.111078 & 0.033391 & 0.212741 \\
\hline $1996 / 97$ & 3792 & 0.537112 & 0.083861 & 0.032674 & 0.005085 & 0.001702 & 0.020019 & 0.091269 & 0.036634 & 0.191644 \\
\hline $1998 / 99$ & 4469.54 & 0.560785 & 0.102451 & 0.026924 & 0.003937 & 0.002770 & 0.023821 & 0.083881 & 0.021377 & 0.174055 \\
\hline $2001 / 02$ & 5730.6 & 0.577287 & 0.084633 & 0.023104 & 0.004321 & 0.003927 & 0.030476 & 0.078596 & 0.035487 & 0.162169 \\
\hline $2004 / 05$ & 7781.8 & 0.539130 & 0.064664 & 0.025831 & 0.003361 & 0.004372 & 0.033679 & 0.077334 & 0.044930 & 0.206698 \\
\hline $2005 / 06$ & 9120.6 & 0.475714 & 0.061816 & 0.024196 & 0.002020 & 0.006396 & 0.032765 & 0.087889 & 0.054925 & 0.254278 \\
\hline $2007 / 08$ & 11260.93 & 0.484886 & 0.060303 & 0.023761 & 0.001368 & 0.007889 & 0.033121 & 0.100423 & 0.059942 & 0.228308 \\
\hline $2010 / 11$ & 17113.08 & 0.544260 & 0.054292 & 0.023008 & 0.001288 & 0.005585 & 0.033248 & 0.087239 & 0.055815 & 0.195265 \\
\hline $2011 / 12$ & 19138.88 & 0.502741 & 0.061771 & 0.023180 & 0.000744 & 0.007632 & 0.036727 & 0.079618 & 0.062461 & 0.225127 \\
\hline
\end{tabular}


Table A3: Average income, by group in urban and rural Pakistan

\begin{tabular}{lcccccccc}
\hline & \multicolumn{2}{c}{$1984 / 85$} & \multicolumn{2}{c}{$1985 / 86$} & \multicolumn{2}{c}{$\mathbf{1 9 8 6 / 8 7}$} & \multicolumn{2}{c}{$\mathbf{1 9 8 7 / 8 8}$} \\
\cline { 2 - 9 } Income group & Urban & Rural & Urban & Rural & Urban & Rural & Urban & Rural \\
\hline Up to 600 & 477.21 & 462.53 & 495.56 & 475.71 & 483.8 & 479.08 & 491.39 & 488.65 \\
$601-700$ & 661.93 & 656.07 & 666.29 & 655.85 & 670.99 & 658.59 & 663.71 & 655.62 \\
$701-800$ & 765.61 & 754.62 & 767.06 & 754.23 & 761.51 & 759.16 & 766.81 & 757.09 \\
$801-1000$ & 924.74 & 904.37 & 922.12 & 906.75 & 926.45 & 905.92 & 928.05 & 905.69 \\
$1001-1500$ & 1255.4 & 1236.64 & 1273.94 & 1238.52 & 1280.29 & 1249.23 & 1283.46 & 1253.62 \\
$1501-2000$ & 1756.85 & 1721.22 & 1756.99 & 1727.2 & 1773.53 & 1722.48 & 1759.62 & 1739.03 \\
$2001-2500$ & 2260.06 & 2214.12 & 2272.49 & 2228.6 & 2269.02 & 2220.99 & 2271.85 & 2223.48 \\
$2501-3000$ & 2759.11 & 2706.77 & 2771.38 & 2714.73 & 2763.12 & 2722.45 & 2787.39 & 2719.8 \\
$3001-3500$ & 3273.45 & 3207.14 & 3263.31 & 3218.79 & 3277.37 & 3230.54 & 3265.79 & 3231.17 \\
3501-4000 & 3762.77 & 3751.16 & 3749.44 & 3741.97 & 3773.71 & 3747.43 & 3758.64 & 3714.37 \\
$4001-4500$ & 4270.72 & 4210.36 & 4257.48 & 4226.93 & 4243.96 & 4224.36 & 4273.34 & 4213.83 \\
4501 and & 8037.39 & 7808.96 & 7056.31 & 7216.56 & 7456.72 & 7412.58 & 8206.97 & 7084.31 \\
above & & & & & & & & \\
\hline
\end{tabular}

\begin{tabular}{|c|c|c|c|c|c|c|c|c|}
\hline \multirow[b]{2}{*}{ Income group } & \multicolumn{2}{|c|}{$1990 / 91$} & \multicolumn{2}{|c|}{$1992 / 93$} & \multicolumn{2}{|c|}{$1996 / 97$} & \multicolumn{2}{|c|}{ 1998/99 } \\
\hline & Urban & Rural & \multirow{2}{*}{$\begin{array}{c}\text { Urban } \\
665\end{array}$} & \multirow{2}{*}{$\begin{array}{c}\text { Rural } \\
658\end{array}$} & \multirow{2}{*}{$\begin{array}{c}\text { Urban } \\
569\end{array}$} & Rural & \multirow{2}{*}{$\begin{array}{c}\text { Urban } \\
643\end{array}$} & \multirow{2}{*}{$\begin{array}{c}\text { Rural } \\
693\end{array}$} \\
\hline Up to 1000 & 491.39 & 488.65 & & & & 746 & & \\
\hline 1001-1500 & 663.71 & 655.62 & 1299 & 1283 & 1309 & 1287 & 1289 & 1282 \\
\hline $1501-2000$ & 766.81 & 757.09 & 1788 & 1766 & 1794 & 1783 & 1786 & 1784 \\
\hline 2001-2500 & 928.05 & 905.69 & 2288 & 2243 & 2279 & 2274 & 2262 & 2275 \\
\hline 2501-3000 & 1283.46 & 1253.62 & 2763 & 2746 & 2793 & 2759 & 2780 & 2749 \\
\hline $3001-3500$ & 1759.62 & 1739.03 & 3278 & 3245 & 3282 & 3257 & 3275 & 3257 \\
\hline $3501-4000$ & 2271.85 & 2223.48 & 3750 & 3751 & 3783 & 3752 & 3778 & 3759 \\
\hline $4001-5000$ & 2787.39 & 2719.8 & 4479 & 4424 & 4538 & 4485 & 4538 & 4473 \\
\hline 5001-6000 & 3265.79 & 3231.17 & 5495 & 5456 & 5505 & 5494 & 5522 & 5471 \\
\hline 6001-7000 & 3758.64 & 3714.37 & 6504 & 6466 & 6497 & 6473 & 6520 & 6499 \\
\hline \multirow[t]{2}{*}{$7001 \&$ above } & 4273.34 & 4213.83 & 12912 & 11537 & 12382 & 11277 & 15050 & 12419 \\
\hline & \multicolumn{3}{|c|}{ 2001/02 } & \multicolumn{2}{|c|}{$2004 / 05$} & \multicolumn{3}{|c|}{$2005 / 06$} \\
\hline Income group & & an & Rural & Urban & Rural & & Urban & Rural \\
\hline 1st & & 06.1 & 4258.9 & 6203 & 5446 & & 6497 & 6768 \\
\hline 2nd & & 07.3 & 4966.9 & 7239 & 6588 & & 8571 & 8339 \\
\hline $3 r d$ & & 67.9 & 5582.2 & 8549 & 7104 & & 10108 & 9670 \\
\hline 4th & & 86.2 & 6268.8 & 10462 & 8273 & & 10747 & 11924 \\
\hline \multirow[t]{2}{*}{5 th } & & 02.5 & 8913.7 & 19233 & 12658 & & 21954 & 19277 \\
\hline & \multicolumn{2}{|c|}{$2006 / 07$} & & 2010/11 & & & 2011/12 & \\
\hline Income group & \multicolumn{2}{|c|}{ Urban } & Rural & Urban & Rural & & Urban & Rural \\
\hline 1 st & \multicolumn{2}{|c|}{8744.19} & 7639.08 & 11970.1 & 11265.2 & & 3844.8 & 13221 \\
\hline 2nd & \multicolumn{2}{|c|}{11018.6} & 9576.5 & 16481.93 & 13613.4 & & 7673.6 & 16578 \\
\hline $3 r d$ & \multicolumn{2}{|c|}{11872.3} & 10900.7 & 17382.76 & 16617.6 & & 1306.5 & 19342 \\
\hline 4th & \multicolumn{2}{|c|}{13238.9} & 13219.4 & 22295.92 & 19921.5 & & 6755 & 23203 \\
\hline 5 th & \multicolumn{2}{|c|}{26163.8} & 22807.5 & 40876.22 & 33932.5 & & 1484 & 33977 \\
\hline
\end{tabular}


Table A4: Energy expenditure trends in urban and rural Pakistan

\begin{tabular}{lcccc}
\hline \multirow{2}{*}{ Year } & \multicolumn{4}{c}{ Urban Pakistan } \\
\cline { 2 - 5 } & $\begin{array}{c}\text { Expenditure on } \\
\text { firewood }\end{array}$ & $\begin{array}{c}\text { Expenditure on } \\
\text { kerosene oil }\end{array}$ & $\begin{array}{c}\text { Expenditure on } \\
\text { gas }\end{array}$ & $\begin{array}{c}\text { Expenditure on } \\
\text { electricity }\end{array}$ \\
\hline $1984 / 85$ & 22.23427 & 13.72124 & 20.96172 & 38.83903 \\
$1985 / 86$ & 24.14653 & 14.13139 & 22.72637 & 40.28394 \\
$1986 / 87$ & 24.42215 & 14.30326 & 20.64720 & 43.01023 \\
$1987 / 88$ & 24.49183 & 14.31586 & 22.66483 & 48.47045 \\
$1990 / 91$ & 30.48453 & 25.20105 & 36.56515 & 87.48478 \\
$1992 / 93$ & 35.27509 & 21.56377 & 48.33485 & 99.51616 \\
$1996 / 97$ & 49.31645 & 20.69429 & 64.26718 & 140.5628 \\
$1998 / 99$ & 50.20477 & 19.69146 & 77.53706 & 197.7952 \\
$2001 / 02$ & 55.96096 & 14.09478 & 143.0376 & 347.0682 \\
$2004 / 05$ & 90.11383 & 8.730361 & 165.7926 & 450.0597 \\
$2005 / 06$ & 88.57702 & 7.856282 & 194.0576 & 509.5561 \\
$2007 / 08$ & 96.93830 & 3.730800 & 213.8770 & 564.6958 \\
$2010 / 11$ & 114.8556 & 2.822764 & 276.8318 & 968.4899 \\
\hline
\end{tabular}

Rural Pakistan

\begin{tabular}{lcccc} 
Year & $\begin{array}{c}\text { Expenditure on } \\
\text { firewood }\end{array}$ & $\begin{array}{c}\text { Expenditure on } \\
\text { kerosene oil }\end{array}$ & $\begin{array}{c}\text { Expenditure on } \\
\text { gas }\end{array}$ & $\begin{array}{c}\text { Expenditure on } \\
\text { electricity }\end{array}$ \\
\hline $1984 / 85$ & 55.53736 & 12.28910 & 1.251229 & 10.79753 \\
$1985 / 86$ & 55.94176 & 13.14764 & 0.889215 & 10.97507 \\
$1986 / 87$ & 59.50694 & 11.95411 & 1.400984 & 16.16127 \\
$1987 / 88$ & 58.36189 & 12.16361 & 1.958828 & 15.51600 \\
$1990 / 91$ & 74.63838 & 18.34280 & 4.313951 & 36.86466 \\
$1992 / 93$ & 96.28753 & 24.30594 & 4.953338 & 41.12906 \\
$1996 / 97$ & 123.8983 & 19.28417 & 6.455390 & 75.91335 \\
$1998 / 99$ & 120.3364 & 17.59563 & 12.37843 & 106.4694 \\
$2001 / 02$ & 132.3970 & 24.76356 & 22.50374 & 174.6481 \\
$2004 / 05$ & 201.0148 & 26.15832 & 34.0197 & 262.0854 \\
$2005 / 06$ & 220.6841 & 18.42712 & 85.33484 & 298.8354 \\
$2007 / 08$ & 267.56605 & 15.40365 & 88.83529 & 372.9693 \\
$2010 / 11$ & 393.7394 & 22.03615 & 95.57117 & 386.2669 \\
\hline
\end{tabular}




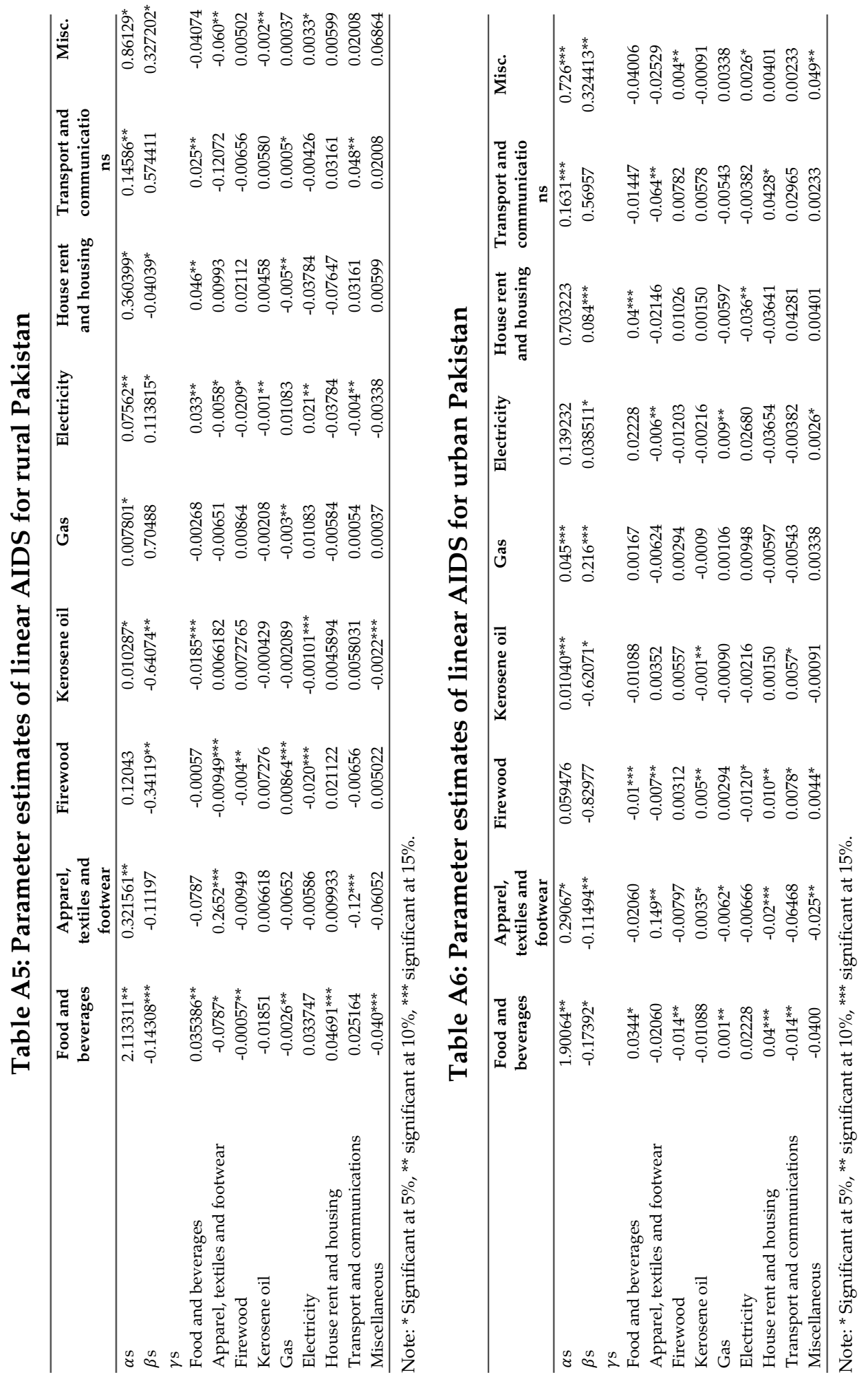




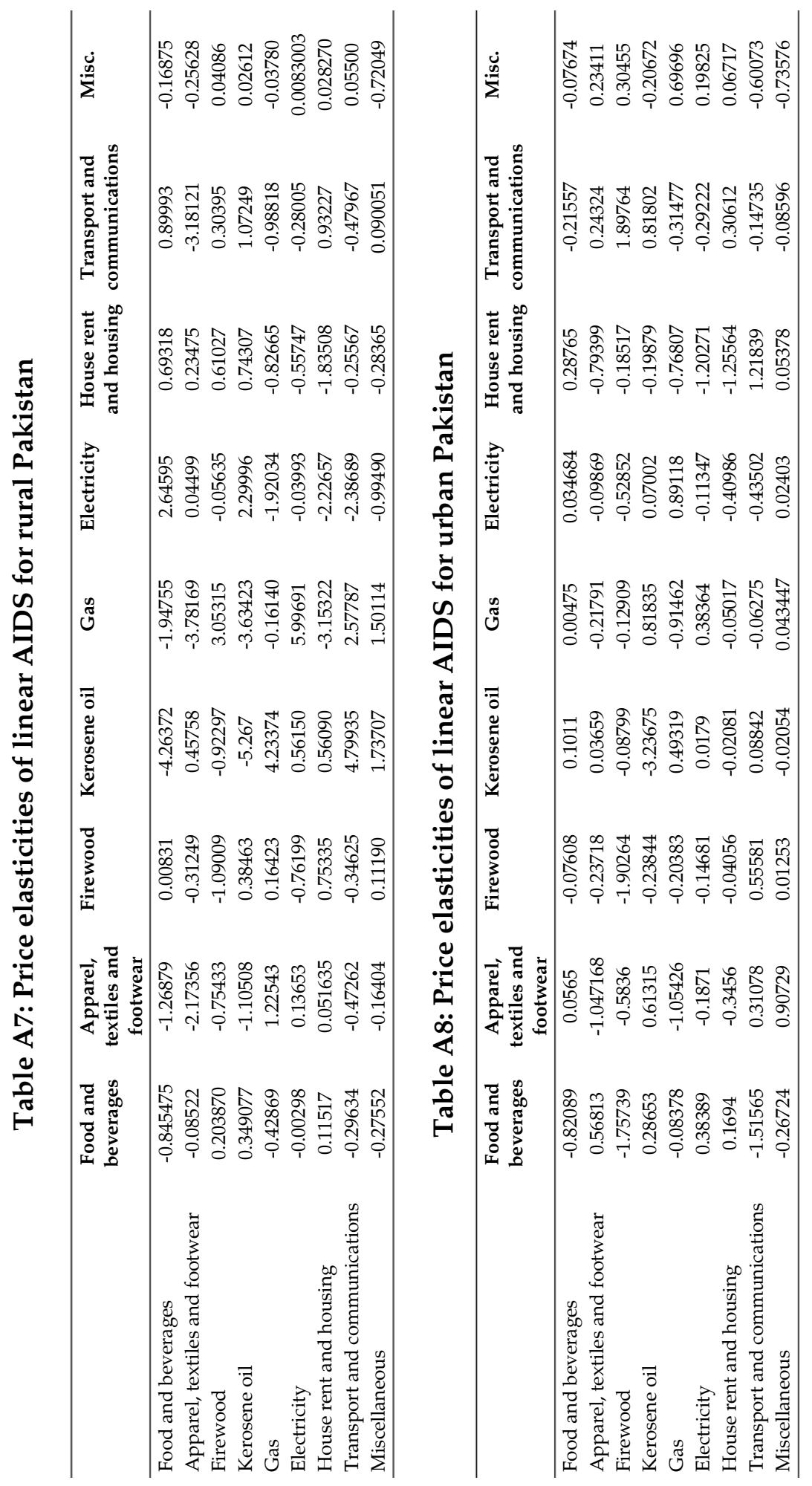

